\title{
EFFECTS OF PHARMACIST COUNSELING ON COMPLIANCE AND INTERNATIONAL NORMALIZED RATIO SCORE ON OUTPATIENTS RECEIVING WARFARIN AT DR. HASAN SADIKIN BANDUNG HOSPITAL WEST JAVA, INDONESIA
}

\author{
NORISCA ALIZA PUTRIANA ${ }^{1 *}$, KERI LESTARI ${ }^{1}$, MELISA INTAN BARLIANA ${ }^{1}$, SRI HARTINI ${ }^{2}$ \\ ${ }^{1}$ Department of Pharmaceutical and Technology Pharmacy, Faculty of Pharmacy, Universitas Padjadjaran, Indonesia. ${ }^{2}$ Department of \\ Pharmacy Instalation, Dr. Hasan Sadikin Hospital, Indonesia. Email: norisca.aliza@gmail.com
}

Received: 25 October 2016, Revised and Accepted: 24 January 2017

\section{ABSTRACT}

Objective: Warfarin is a derivate of coumarin, which is usually prescribed as an oral anticoagulant for treatment and prevention of thromboembolic disorders. The aim of present research is to analyze the influence of pharmacist counseling on compliance and international normalized ratio (INR) score recovery on warfarin management.

Methods: Design in this research used mixed method, combination of qualitative and quantitative method. Qualitative data were used for completing quantitative data. Qualitative method used a content analysis with interview. Quantitative method used a quasi-experimental method with control groups, pre-test, and post-test design. Data were analyzed by Wilcoxon test and Mann-Whitney test at significance level $p \leq 0.05$ and multivariate analysis covariate.

Results: Data were collected from 80 patients with rheumatic heart disease (42.5\%), atrial fibrillation (17.5\%), deep vein thrombosis (10\%), rheumatic mitral valve disease (10\%), prosthetic heart (7.5\%), other (22.5\%). The numbers of patients whose INR was in the therapeutic range for each indication was not statistically different between before and after receiving counseling ( $p>0.05$ ), Patients' behavior compliance of warfarin therapy had increased after receiving the counseling service $(p<0.05)$. The result of presents research is pharmacist counseling affected behavior compliance before and after counseling $(\mathrm{p}<0.05)$ but not for INR $(\mathrm{p}>0.05)$.

Conclusion: Pharmacist counseling can improve behavior compliance but not improve INR target. The effect of warfarin to every individual not only affected by behavior compliance but also several factors could influence effect of warfarin is clinical factors, non-clinical factors, and genetic factors. Clinical factors that were influenced were age, gender, pharmacokinetic and pharmacodynamic variability in patients.

Keywords: Warfarin, Counseling, Compliance, International normalized ratio.

(C) 2017 The Authors. Published by Innovare Academic Sciences Pvt Ltd. This is an open access article under the CC BY license (http://creativecommons. org/licenses/by/4. 0/) DOI: http://dx.doi.org/10.22159/ajpcr.2017.v10s2.19492

\section{INTRODUCTION}

Warfarin was a differential of coumarin, usually prescribed as an oral anticoagulant to cure or prevent thrombotic diseases, namely, myocardial infarction, ischemic stroke, venus thrombosis, heart valve replacement, and atrial fibrillation [1]. Warfarin had a small therapeutic index and gave a big different response between individual and patient. Dosage insufficiency would lead to failure of preventing thromboembolism, while its overbalance would lead to bleeding risk [2]. Therefore, monitoring toward the success of warfarin therapy to each patient was required, measured with prothrombin time parameters, stated by prothrombin time-international normalized ratio (PT-INR). The study about PT-INR determination during warfarin consumption was examined exclusively, at least 4-5 times a week based on therapeutic dosage and stable INR score. The desired INR score was usually 2-3 based on the type of disease [3].

The previous study conducted by a researcher focused on monitoring of warfarin therapy through PT-INR parameter at a hospital in Bandung showed that the patient's INR score was below the range of 2-3. The highest weekly dosage use was $7 \mathrm{mg}$ to 63 patients out of 80 patients, with the average INR score of 1.4. It exemplified that the dosage has not reached the target of INR [4].

Some research indicated that patients' lack of knowledge about warfarin and lack of training by medical personnel related to bad anticoagulant monitoring and increasing frequency of incident of bleeding side effect [5]. Patients' lack of knowledge about warfarin also related to patients' discompliance toward warfarin therapy. Discompliance is related to excessive variation of anticoagulant monitoring [6].
Noncompliance with drug therapy is manifested in numerous ways, such as failing to have a prescription filled, getting a prescription filled but failing to take the drug, taking only a portion of a prescribed drug, or not following the dose or frequency instructions. Preventing and correcting noncompliance with a drug regimen are crucial functions of pharmacists in their roles as practitioners of pharmaceutical care. In anticoagulation clinics, the pharmacist's role can be especially important because of the evidence linking warfarin noncompliance with negative outcomes. For example, one study showed that noncompliance (as measured by a pill count) of $<80 \%$ was significantly linked with severe thromboembolic events (transient ischemic attack, stroke). In another study, 28\% of INR values above 6 (therapeutic range 2-3) were due to poor compliance, thus predisposing patients to an increased risk of hemorrhagic events [7].

Pharmacists are in a unique position to play a vital role in helping patients to cope up with their disease and make informed decisions regarding management and medication by patient counseling [8]. A study was proposed to analyze the influence of pharmacist counseling on compliance and INR score recovery on warfarin management.

\section{METHODS}

A study was conducted in the outpatient receiving warfarin at teaching Hospital DR. Hasan Sadikin Hospital, West Java, Indonesia, with the approval of the Institutional Ethics Committee and the consent of the study participants. The study population consisted of 80 patients who were divided into counseling group and control group. Inclusion criteria were outpatient of cardioclinic who applied warfarin therapy $\geq 3$ months, aged $\geq 18$-year-old, had PT-INR data from laboratory, 
had complete medical records, regular doctor visit frequency, and willing to participate in this study. Exclusion criteria were patients who were not able to be followed up due to passing away, move to other medical treatment, had incomplete medical records, and lost contact.

This study used mixed method, combination between qualitative and quantitative research method. It also applied embedded design where qualitative data were used to support quantitative data. Qualitative method applied in this study was in the form of content analysis with interview, while quantitative method was in the form of quasiexperimental with the control group of pre-test and post-test design. Pre-test and post-test design were created using purposive sampling based on researcher's consideration or criteria which were related to intention and purpose, conducted by taking case or respondent that fulfilled inclusion and exclusion criteria. In this design, each experiment unit was treated by measuring two times. First measurement was conducted before counseling, while second measurement conducted counseling organized by pharmacist. In this study, intervention given in the form of counseling. The patient's condition was controlled during the period of the research to identify patient's therapy outcomes by considering patient's compliance and INR score. Patient's compliance was indicated by fulfilling questionnaire of compliance, employing Morisky scale, which consists of eight questions. The INR score was controlled every 3 months before and after the counseling was organized.

\section{Morisky 8-item medication adherence questionnaire}

Medication adherence behavior of the patients was assessed at each follow-up for both the groups using a 8-item scale. Scoring was given based on the scheme of "Yes" $=0$ and "No" $=1$. The degree of adherence was determined according to the score resulting from the sum of all the correct answers: High adherence ( 8 points), average adherence ( 6 to $<8$ points), and poor adherence ( $<6$ points).

\section{Statistical analysis}

Statistical analysis was conducted using bivariate analysis to identify the relationship between free variable and dependent variable. A test employed in this study was a paired sample discrimination test. Continued data measurement on the questionnaire before and after counseling was examined using paired test if the data were distributed normally. However, if the data did not fulfill the requirements (were not distributed normally), categorical data measurement was conducted using Wilcoxon test and Mann-Whitney test for non-paired sample.

\section{RESULTS}

This study involved 80 patients who were divided into two groups, namely, counseling group, consisting 40 patients and 40 other patients were in control group. Control group had more female patients than male ones. The greatest number of disease indicated in those two groups was rheumatic heart disease (Table 1).

The present study exemplified that the patients' compliance index in conducting warfarin therapy increased after counseling had been given. Respondents who were categorized compliance, increased after counseling by $17.5 \%$ (Table 2 ).

There were differences between INR score before and after the counseling was given. The expected INR score for those patients is between 2 and 3 . Several months before counseling, percentage of respondents with INR score $2-3$ was $40 \%$ in average and grew up to $70 \%$ in the $1^{\text {st }}$ month after counseling. While in the $2^{\text {nd }}$ month, the percentage reduced (42.5\%) in the $2^{\text {nd }}$ month, and raised (52.5\%) after counseling was given (Table 3 and Fig. 1).

Number of respondents who had INR score $>3$ appeared mostly (30\%) before counseling (in the $3^{\text {rd }}$ month), decreased in the $1^{\text {st }}$ month $(17.5 \%)$, increased in the $2^{\text {nd }}$ month $(27.5 \%)$, and decreased to $12.5 \%$ in the $3^{\text {rd }}$ month after counseling was given. The number of respondents with INR score below 2 in the $1^{\text {st }}$ month was the lowest among others,
Table 1: Baseline characteristics of study population

\begin{tabular}{|c|c|c|}
\hline \multirow[t]{2}{*}{ Characteristics } & \multicolumn{2}{|l|}{$n=40 \mathrm{n}(\%)$} \\
\hline & Counseling group & Control group \\
\hline \multicolumn{3}{|l|}{ Gender } \\
\hline Male & $13(32.5)$ & $15(37.5)$ \\
\hline Female & $27(67.5)$ & $25(62.5)$ \\
\hline \multicolumn{3}{|l|}{ Age (years) } \\
\hline $18-40$ & $12(30)$ & $11(27.5)$ \\
\hline $41-50$ & $11(27.5)$ & $12(30)$ \\
\hline $51-590$ & $8(20)$ & $14(35)$ \\
\hline $60-70$ & $9(22.5)$ & $3(7.5)$ \\
\hline \multicolumn{3}{|l|}{ Education status } \\
\hline Primary school & $18(45)$ & $19(47.5)$ \\
\hline Junior high school & $9(22.5)$ & $6(15)$ \\
\hline High school & $7(17.5)$ & $10(25)$ \\
\hline D1 & $1(2.5)$ & - \\
\hline D3 & $1(2.5)$ & - \\
\hline Graduates & $4(10)$ & $5(12.5)$ \\
\hline \multicolumn{3}{|l|}{ Activity } \\
\hline Homemaker & $22(55)$ & $19(47.5)$ \\
\hline Pensioner & $6(15)$ & $2(5)$ \\
\hline Civil Servant & $3(7.5)$ & $5(12.5)$ \\
\hline Private & $3(7.5)$ & $9(22.5)$ \\
\hline Entrepreneur & $3(7.5)$ & $4(10)$ \\
\hline Laborer & $2(5)$ & - \\
\hline Student & $1(2.5)$ & $1(2.5)$ \\
\hline \multicolumn{3}{|l|}{ Indication } \\
\hline Rheumatic heart disease & $17(42.5)$ & $13(32.5)$ \\
\hline Atrial fibrillation & $7(17.5)$ & - \\
\hline $\begin{array}{l}\text { Rheumatic mitral valve } \\
\text { disease }\end{array}$ & $4(10)$ & $6(15)$ \\
\hline Deep vein thrombosis & $4(10)$ & $2(5)$ \\
\hline Prosthetic heart valve & $3(3)$ & $1(2.5)$ \\
\hline $\begin{array}{l}\text { Hypertension heart } \\
\text { disease }\end{array}$ & $3(3)$ & $1(2.5)$ \\
\hline Cardiomyopathy & $1(2.5)$ & $2(2.5)$ \\
\hline $\begin{array}{l}\text { Coronary atherosclerotic } \\
\text { disease }\end{array}$ & $1(2.5)$ & $7(17.5)$ \\
\hline
\end{tabular}

Table 2: Frequency distribution of behavior adherence

\begin{tabular}{lllll}
\hline Variable & \multicolumn{3}{l}{$\mathbf{n}=\mathbf{4 0}(\mathbf{\%})$} & \\
\cline { 2 - 5 } & \multicolumn{2}{l}{ Counseling group } & \multicolumn{2}{l}{ Control group } \\
\cline { 2 - 5 } & Before & After & Before & After \\
\hline Compliance & $29(72.5)$ & $36(90)$ & $24(60)$ & $25(55)$ \\
Noncompliance & $11(27.5)$ & $4(10)$ & $16(40)$ & $15(35)$ \\
\hline
\end{tabular}

Table 3: Frequency distribution of INR on counseling group

\begin{tabular}{llllllll}
\hline INR & \multicolumn{2}{l}{ Month } & & & \\
\cline { 2 - 3 } & \multicolumn{2}{l}{ Before counseling (\%) } & & \multicolumn{3}{l}{ After counseling (\%) } \\
\cline { 2 - 3 } \cline { 6 - 7 } & $\mathbf{1}$ & $\mathbf{2}$ & $\mathbf{3}$ & & $\mathbf{1}$ & $\mathbf{2}$ & $\mathbf{3}$ \\
\hline$>3$ & $5(12.5)$ & $9(22.5)$ & $12(30)$ & & $7(17.5)$ & $11(27.5)$ & $5(12.5)$ \\
$2-3$ & $17(42.5)$ & $18(45)$ & $16(40)$ & & $28(70)$ & $17(42.5)$ & $21(52.5)$ \\
$<2$ & $18(45)$ & $13(32.5)$ & $12(30)$ & & $5(12.5)$ & $12(30)$ & $14(35)$ \\
Total & 40 & 40 & 40 & 40 & 40 & 40 \\
\hline
\end{tabular}

INR: International normalized ratio

but it raised in the $2^{\text {nd }}$ and $3^{\text {rd }}$ months $(30 \%$ and $35 \%)$. INR $>3$ and $<2$ were considered unexpected scores because of insufficient dosage leads to failure of preventing thromboembolism $(\mathrm{INR}<2)$, while too much dosage would lead to increasing bleeding risk (INR $>3$ ). INR score in the control group was different with that of counseling group's. The number of patients who had INR score 2-3 were 17 patients in average, it was less than counseling group (Table 4 and Fig. 2). 
Table 4: Frequency distribution of INR on control group

\begin{tabular}{|c|c|c|c|c|c|c|}
\hline \multirow[t]{3}{*}{ INR } & \multicolumn{6}{|l|}{ Month } \\
\hline & \multicolumn{3}{|c|}{ Before counseling (\%) } & \multicolumn{3}{|c|}{ After counseling (\%) } \\
\hline & 1 & 2 & 3 & 1 & 2 & 3 \\
\hline$>3$ & $7(17.3)$ & $5(12.5)$ & $10(25)$ & $8(20)$ & $7(17.5)$ & $3(7.5)$ \\
\hline $2-3$ & $15(37.5)$ & $17(42.5)$ & 15 (37.5) & $19(47.5)$ & $16(40)$ & $18(45)$ \\
\hline$<2$ & $18(45)$ & $18(45)$ & 15 (37.5) & $13(32.5)$ & $17(42.5)$ & $19(47.5)$ \\
\hline Total & 40 & 40 & 40 & 40 & 40 & 40 \\
\hline
\end{tabular}

INR: International normalized ratio

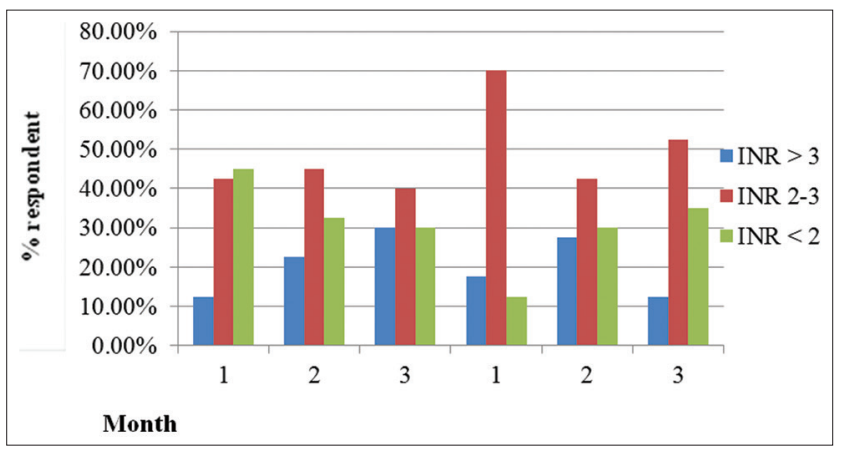

Fig. 1: International normalized ratio score on counseling group

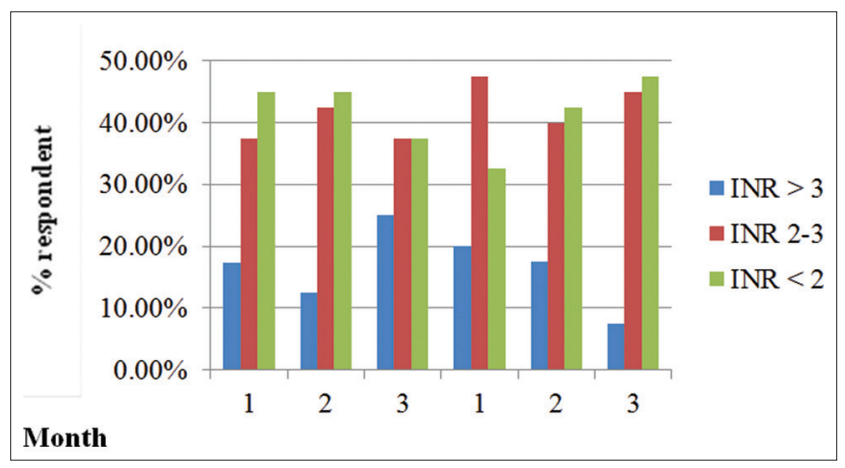

Fig. 2: International normalized ratio score on control group

The result of Wilcoxon test of paired data on warfarin patient's compliance before and after counseling showed that the score of $\mathrm{p}$-value gained was 0.000. Moreover, the result of Mann-Whitney test of unpaired data demonstrated that the score of p-value of warfarin patient's therapy in both counseling group and control group was 0.000 or less than alpha $(0.000<0.05)$. It exemplified that there was a significant difference between patient's compliance before and after counseling given by pharmacist, and there was also significant differences between counseling and control groups.

The result of Wilcoxon test indicated that scores of p-value gained were in the amount of $0.789,0.943$, and 0.1444 (before and after counseling) and $0.105,0.185$, and 0.226 (after counseling and control). It showed that there was no significant differences of the patient's INR score before and after counseling given.

\section{DISCUSSION}

There was different meaning between patient's compliance before and after counseling and that between counseling and control group. The results of this study demonstrated that giving counseling to the patients could improve their compliance toward regiment of warfarin therapy. Health trust model portrayed that motivation or intention determined health behavior.
A study conducted by Burge et al. showed that cultural and educational background influenced medical knowledge. Medical knowledge, social relationship, age, and language had positive impact to medical compliance. There were some factors that influenced medical compliance, namely, patient's internal factors - age, sex, personality traits, belief toward healthcare, health status, disease, medical regiment, financial factor, and those coming from medical personnel [9].

Patient's compliance improved after counseling had been conducted. It was shown by compliance parameter and medical treatment card. Compliance improvement would proportional to INR score improvement. This study demonstrated that the patient's compliance toward warfarin therapy was not proportional to the result of INR improvement. It could happen because of clinical factors - age and sex and non-clinical factors - dosage, interaction with medicine, interaction with food, alcohol, and vitamin $\mathrm{K}$ intake, and genetical factors. Genetical polymorphism could influence individual response toward pharmacological active substance and interaction between them was often named as pharmacogenomic. Pharmacogenomical information would predict about the effectiveness of dosage, therapeutic effect, and toxic effect of a medicine [10]. A study conducted by Yoshizawa et al. showed that polymorphism CYP2C9 and vitamin K epoxide reductase complex subunit 1 (VKORC1) contribute helpfully to warfarin's efficacy and toxicity. CYP2C9 was an enzyme that was useful for warfarin metabolism, while VKORC1 was a target gene where warfarin works [11]. According to the result of a study about pharmacogenetic conducted by Taofik et al. toward population of Indonesian who use warfarin, exemplifies that age and genetical variation of CYP2C9 and VKORC1 influences warfarin response, namely, the result of PT-INR, index of pharmacodynamic, index of pharmacokinetics, and S-warfarin concentration on patients who consume low-dosage warfarin $(1 \mathrm{mg})$. Based on the result mentioned above, INR monitoring should be done regularly, especially to patient who has various genotype VKORC11639AA and $C Y P 2 C 9^{*} 1 /{ }^{*} 3$, who highly risky to suffer from bleeding due to dosage overbalance. In addition, regular monitoring should be performed to patients who have genotype VKORC1-1639GG and CYP2C9*1/*1, who highly risk to suffer from thromboembolic when it was lack of dosage [12].

The results of this study exemplified that counseling improves patients' compliance to take medicine. This behavior did not change the patients' compliance directly, but it happened step by step. It related to their awareness and belief toward given information and strong will to recover so that they get better quality of life.

According to the result of interview, it was revealed that there were some factors obstructing the patients' compliance, namely, financial factor, sleeping before 10 p.m. or required time to take warfarin, and family support. Counseling was a place for patients to obtain information and health service to help them independently nursing. This study revealed that although counseling was given, it did not change all of the patient's behavior directly to follow the recommended warfarin therapy regiment. There were still seven respondents whose INR score was $>3$ in the $1^{\text {st }}$ month after intervention, 11 and five respondents in the $2^{\text {nd }}$ and $3^{\text {rd }}$ month after counseling. In addition, there were five, 12 , and 14 respondents whose INR score was $<2$ after counseling due to several factors besides patient's individual compliance, namely, dosage, age, the patient's pharmacokinetics and pharmacodynamic variation, interaction with medicine, vitamin $\mathrm{K}$ intake, and interaction with food. Although the INR score achieved the target of 2-3, it did not have consistent score in each month because there was contribution of a pharmacist in giving counseling and information about warfarin to the respondents, indicated from the improvement of knowledge, perception, and compliance.

The counseling program was welcomed by the patients who became respondents of this study because there was no patient dropping out. The respondents stated that by attending counseling given by 
pharmacist, they recognized and understood about an appropriate warfarin therapy.

The clinical pharmacist could play an important role in this area. To get these outcomes, patients must be educated regularly to improve their compliance. They must be made to understand the need for treatment, benefits, and risk associated with the prescribed medicines and impact of non-adherence to their medications.

\section{CONCLUSION}

Pharmacist counseling gave a significant influence to patient's compliance in warfarin therapy, but it did not have any significant effect to a successful therapy in improving INR score.

\section{REFERENCES}

1. Hirsch J, Dalen JE, Anderson DR, Poller L, Bussey H, Ansell J. Oral anticoagulan: Mechanisms of action, clinical effectiveness and optimal therapeutic range. Chest 2001;119(1):8S-21.

2. Rose P. Audit of anticoagulant therapy. J Clin Pathol 1996;49(1)5-9.

3. Conway DS, Lip G. Atrial fibrillation. Medicine 2002;30:140-4.

4. Aliza N. Monitoring Therapy Warfarin on Outpatients in Bandung Hospital. Skripsi. Bandung, Indonesia: Faculty of Pharmacy Unpad 2010.

5. Tang EO, Lai CS, Lee KK, Wong RS, Cheng G, Chan TY. Relationship between patients' warfarin knowledge and anticoagulation control. Ann Pharmacother 2003;37(1):34-9.

6. Waterman AD, Milligan PE, Bayer L, Banet GA, Gatchel SK, Gage BF. Effect of warfarin nonadherence on control of the International Normalized Ratio. Am J Health Syst Pharm 2004;61(12):1258-64.

7. Orensky IA, Holdford DA. Predictors of noncompliance with warfarin therapy in an outpatient anticoagulation clinic. Pharmacotherapy 2005;25(12):1801-8.

8. Lewis RK, Lasack NL, Lambert BL, Connor SE. Patient counseling - A focus on maintenance therapy. Am J Health Syst Pharm 1997;54(18):2084-98.

9. Burge S, White D, Bajorek E, Bazaldua O, Trevino J, Albright T, et al. Correlates of medication knowledge and adherence: Findings from the residency research network of South Texas. Fam Med2005;37(10):712-8.

10. Yin T, Miyata $\mathrm{T}$. Warfarin dose and the pharmacogenomics of CYP2C9 and VKORC1 - Rationale and perspectives. Thromb Res 2007;120(1):1-10

11. Yoshizawa M, Hayashi H, Tashiro Y, Sakawa S, Moriwaki H, Akimoto T, et al. Effect of VKORC1-1639 G>A polymorphism, body weight, age, and serum albumin alterations on warfarin response in Japanese patients. Thromb Res 2009;124(2):161-6.

12. Rusdiana $\mathrm{T}$, Araki $\mathrm{T}$, Nakamura $\mathrm{T}$, Subarnas A, Yamamoto $\mathrm{K}$. Responsiveness to low-dose warfarin associated with genetic variants of VKORC1, CYP2C9, CYP2C19, and CYP4F2 in an Indonesian population. Eur J Clin Pharmacol 2013;69(3):395-405. 